\title{
Some Comments on the Question Whether Co-Occurrence Data Should Be Normalized
}

\author{
Ludo Waltman and Nees Jan van Eck
}

\begin{tabular}{|l|l|}
\hline \multicolumn{2}{|l|}{ ERIM REPORT SERIES RESEARCH IN MANAGEMENT } \\
\hline ERIM Report Series reference number & ERS-2008-014-LIS \\
\hline Publication & March 2008 \\
\hline Number of pages & 3 \\
\hline Persistent paper URL & http://hdl.handle.net/1765/11810 \\
\hline Email address corresponding author & Iwaltman@few.eur.nl \\
\hline Address & Erasmus Research Institute of Management (ERIM) \\
& RSM Erasmus University / Erasmus School of Economics \\
& Erasmus Universiteit Rotterdam \\
& P.O.Box 1738 \\
& 3000 DR Rotterdam, The Netherlands \\
& Phone: $\quad+31104081182$ \\
& Fax: $\quad+31104089640$ \\
& Email: info@erim.eur.nl \\
& Internet: $\quad$ www.erim.eur.nl \\
\hline
\end{tabular}

Bibliographic data and classifications of all the ERIM reports are also available on the ERIM website: www.erim.eur.nl 
ERASMUS RESEARCH INSTITUTE OF MANAGEMENT

\section{REPORT SERIES}

\section{RESEARCH IN MANAGEMENT}

\begin{tabular}{|l|l|}
\hline \multicolumn{2}{|l|}{ ABSTRACT AND KEYWORDS } \\
\hline Abstract & $\begin{array}{l}\text { In a recent article in JASIST, L. Leydesdorff and L. Vaughan (2006) asserted that raw cocitation } \\
\text { data should be analyzed directly, without first applying a normalization such as the Pearson } \\
\text { correlation. In this communication, it is argued that there is nothing wrong with the widely } \\
\text { adopted practice of normalizing cocitation data. One of the arguments put forward by } \\
\text { Leydesdorff and Vaughan turns out to depend crucially on incorrect multidimensional scaling } \\
\text { maps that are due to an error in the PROXSCAL program in SPSS. }\end{array}$ \\
\hline Free Keywords & $\begin{array}{l}\text { Co-occurrence data, author cocitation analysis, normalization, Pearson correlation, } \\
\text { multidimensional scaling, PROXSCAL }\end{array}$ \\
\hline Availability & $\begin{array}{l}\text { The ERIM Report Series is distributed through the following platforms: } \\
\text { Academic Repository at Erasmus University (DEAR), DEAR ERIM Series Portal } \\
\text { Social Science Research Network (SSRN), SSRN ERIM Series Webpage } \\
\text { Research Papers in Economics (REPEC), REPEC ERIM Series Webpage }\end{array}$ \\
\hline Classifications & $\begin{array}{l}\text { The electronic versions of the papers in the ERIM report Series contain bibliographic metadata } \\
\text { by the following classification systems: } \\
\text { Library of Congress Classification, (LCC) LCC Webpage } \\
\text { Journal of Economic Literature, (JEL), JEL Webpage } \\
\text { ACM Computing Classification System CCS Webpage } \\
\text { Inspec Classification scheme (ICS), ICS Webpage }\end{array}$ \\
\hline
\end{tabular}




\title{
BRIEF COMMUNICATION
}

\section{Some Comments on the Question Whether Co-Occurrence Data Should Be Normalized}

\author{
Ludo Waltman and Nees Jan van Eck \\ Econometric Institute, Erasmus School of Economics, Erasmus University Rotterdam, P.O. Box 1738, \\ 3000 DR Rotterdam, The Netherlands. E-mail: \{lwaltman, nvaneck\}@few.eur.nl
}

In a recent article in JASIST, L. Leydesdorff and L. Vaughan (2006) asserted that raw cocitation data should be analyzed directly, without first applying a normalization such as the Pearson correlation. In this communication, it is argued that there is nothing wrong with the widely adopted practice of normalizing cocitation data. One of the arguments put forward by Leydesdorff and Vaughan turns out to depend crucially on incorrect multidimensional scaling maps that are due to an error in the PROXSCAL program in SPSS.

\section{Introduction}

Recently, Leydesdorff and Vaughan (2006) argued that in the analysis of cocitation (or, more generally, co-occurrence) data, one should not apply a normalization, such as the Pearson correlation or the cosine, to the cocitation matrix. According to Leydesdorff and Vaughan, one should either use raw cocitation data or should base the analysis on the asymmetrical citation matrix rather than on the symmetrical cocitation matrix. The position taken by Leydesdorff and Vaughan has quite far-reaching implications since the practice of analyzing cocitation data by normalizing the cocitation matrix has been widely adopted and used in a large number of studies. In this communication, we oppose the position of Leydesdorff and Vaughan, and we argue that there is nothing wrong with the practice of normalizing cocitation matrices. We reject both arguments against this practice provided by Leydesdorff and Vaughan. Although we focus our attention on author cocitation analysis, our comments apply equally well to other analyses that are based on co-occurrence data.

Received November 21, 2006; revised December 21, 2006; accepted December 22, 2006

(C) 2007 Wiley Periodicals, Inc. • Published online 6 July 2007 in Wiley InterScience (www.interscience.wiley.com). DOI: 10.1002/asi.20647

\section{Comparison with the Mapping of Cities}

The first argument put forward by Leydesdorff and Vaughan (2006) stated that cocitation matrices should not be normalized because such matrices contain proximity data, which are data that can be analyzed directly, without any conversion. According to Leydesdorff and Vaughan, normalization of a cocitation matrix may distort the data in the matrix and should therefore be avoided. Leydesdorff and Vaughan illustrated this point by providing an example in which a matrix of distances between cities is mapped using multidimensional scaling (MDS). In the example, normalization of the distance matrix does indeed distort the data; however, in our opinion, there is an essential difference between mapping cities based on a distance matrix and mapping authors based on a cocitation matrix. When cities are mapped, the resulting map should reflect the distances between the cities. These distances are provided by the distance matrix. When authors are mapped, the resulting map should reflect the similarities between the authors. The cocitation matrix, however, does not directly provide these similarities. Although similarities between authors can be derived from the cocitation matrix, one generally should not simply use the number of cocitations of two authors as a measure of the authors' similarity. If this approach were taken, an author who is frequently cited would, on average, have high similarities to other authors whereas an author who is rarely cited would, on average, have low similarities to other authors. In our opinion, this does not make sense. The number of times an author is cited might be a good measure of the significance of the author's work, but it should have no effect on the extent to which the author is considered similar to other authors. To correct for differences in the number of times authors are cited, cocitation matrices should be normalized, for example, using the Pearson correlation. The normalized cocitation data then can be used as input to MDS. Note that many cocitation studies (e.g., McCain, 1990; White \& Griffith, 1981) 
have used this motivation to justify the normalization of cocitation data.

\section{Mapping Authors Using SPSS PROXSCAL}

The second argument provided by Leydesdorff and Vaughan (2006) against the use of normalized cocitation data is of a more practical nature. Leydesdorff and Vaughan performed an author cocitation analysis of the data studied by Ahlgren, Jarneving, and Rousseau (2003), and made a comparison between the map obtained by applying MDS to the raw cocitation matrix and the map obtained by applying MDS to the cocitation matrix normalized using the Pearson correlation. Leydesdorff and Vaughan observed that the map based on the normalized data is less informative than the map based on the raw data, and they concluded from this that the Pearson correlation distorts cocitation data. Unfortunately, some of the MDS maps presented by Leydesdorff and Vaughan (see Figures 5, 9, and 12 in their article) have not been constructed correctly. This is due to an error in the PROXSCAL program in SPSS, which is the program used by Leydesdorff and Vaughan to construct their maps. In SPSS Version 14.0.0 (and also in some earlier versions of SPSS), the combination of similarity data and the interval transformation is handled incorrectly by PROXSCAL. This can be seen most easily by inspecting the transformation plot provided by PROXSCAL. Using SPSS Version 14.0.0, we replicated the analysis performed by Leydesdorff and Vaughan to check their transformation plots. We applied interval MDS to their normalized cocitation matrix (see Table 9 in Ahlgren et al., 2003), which resulted in a map similar to that in Figure 12 in the Leydesdorff and Vaughan article. When we inspected the transformation plot, we observed a linear function that was either constant or increasing (depending on the choice of the initial configuration). This clearly indicates that Leydesdorff and Vaughan presented MDS maps that were not constructed correctly since in the case of similarity data the transformation plot should always show a decreasing function. One of the programmers of the PROXSCAL program (F. Busing, personal communication, November 21, 2006) confirmed to us that the incorrect maps are caused by an error in PROXSCAL. The error can be dealt with in two ways. In SPSS Version 14.0.0 (and also in some earlier versions of SPSS), rather than the interval transformation one should use a spline transformation of degree one with no interior knots. The latter transformation is equivalent to the interval transformation and works correctly. In SPSS Version 14.0.1 and higher, the PROXSCAL program has been fixed, and the interval transformation can be used without any problems. The corrected versions of Figures 9 and 12 in the Leydesdorff and Vaughan article are displayed in our Figures 1 and 2, respectively. The map in Figure 1 is based on the Pearson correlation between authors' citation profiles (Table 2 in the Leydesdorff \& Vaughan article) while the map in Figure 2 is based on the Pearson correlation between authors' cocitation profiles (Table 9 in Ahlgren et al., 2003). To reduce the effect of local minima, for each map

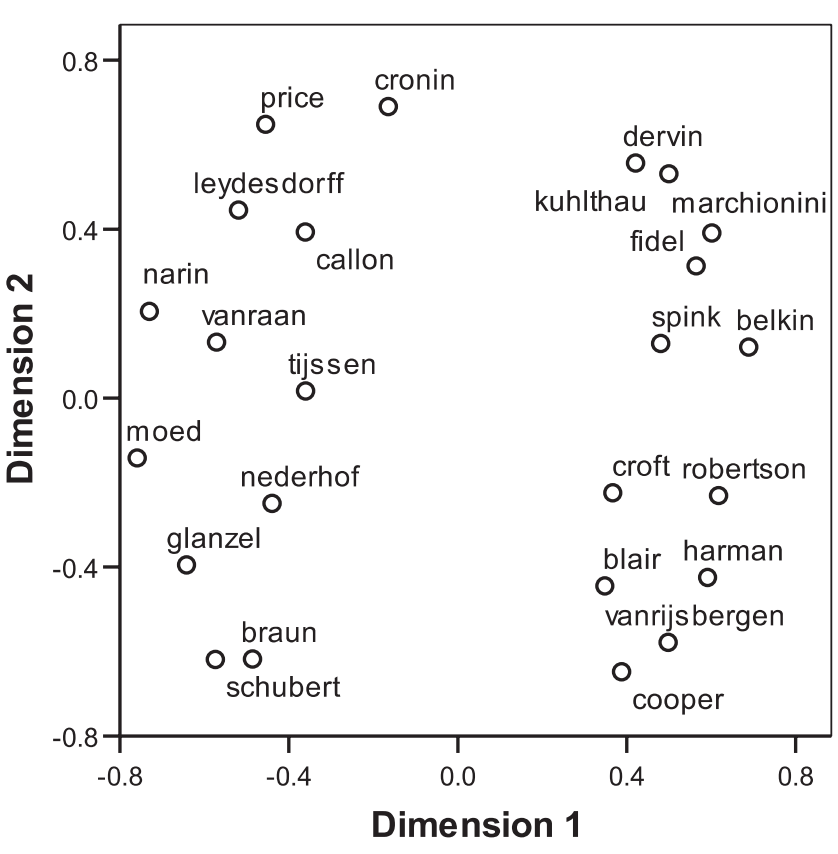

FIG. 1. MDS map based on the Pearson correlation between authors' citation profiles (normalized raw stress $=0.0441$ ). This is the corrected version of Figure 9 in the Leydesdorff and Vaughan (2006) article.

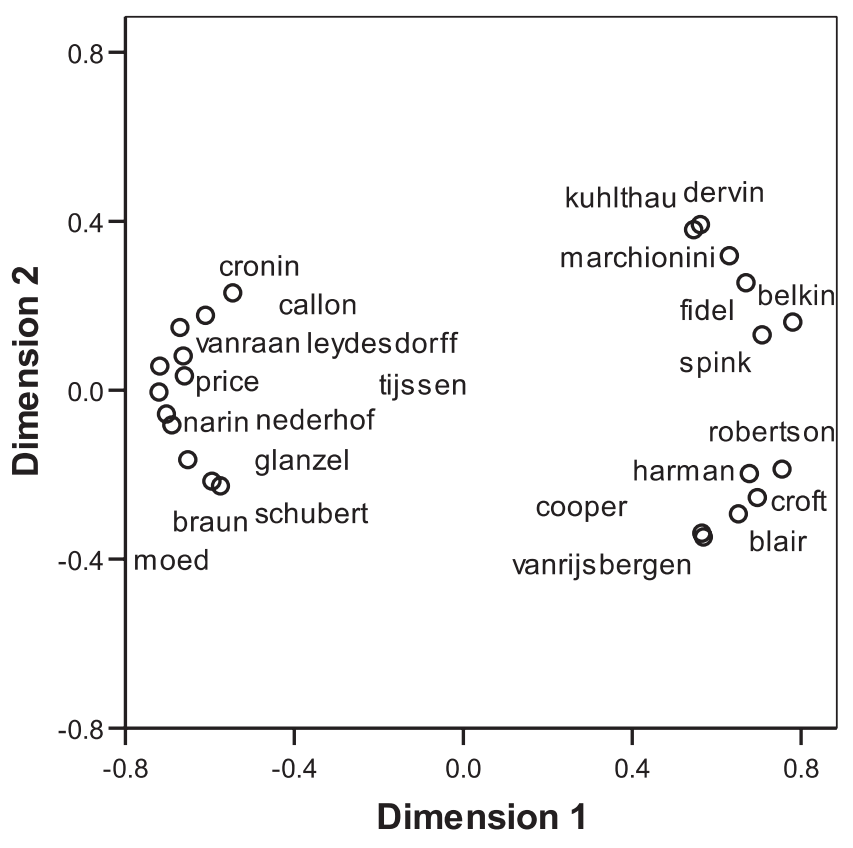

FIG. 2. MDS map based on the Pearson correlation between authors' cocitation profiles (normalized raw stress $=0.0018$ ). This is the corrected version of Figure 12 in the Leydesdorff and Vaughan (2006) article.

PROXSCAL was run from 10 randomly chosen initial configurations. By comparing Figure 2 in this communication with Figure 11 in the Leydesdorff and Vaughan article, we can reconsider Leydesdorff and Vaughan's conclusion that the Pearson correlation distorts cocitation data. The conclusion is clearly incorrect. In Figure 2, the separation between the information retrieval researchers and the scientometricians 
is even better than in Figure 11 in the Leydesdorff and Vaughan article, which seems to indicate that the use of the Pearson correlation has a positive rather than a negative effect on the quality of a cocitation map.

\section{Citation Data Versus Cocitation Data}

Leydesdorff and Vaughan (2006) further argued that it is advisable to use asymmetrical citation matrices instead of symmetrical cocitation matrices as the underlying data for a cocitation map. This advice also needs to be reconsidered using the corrected MDS maps. The maps in Figure 1 in this communication and Figure 8 in the Leydesdorff and Vaughan article are based on citation data while the maps in Figure 2 in this communication and Figure 11 in the Leydesdorff and Vaughan article are based on cocitation data. The maps based on cocitation data show a better separation between the information retrieval researchers and the scientometricians than the maps based on citation data. Therefore, there seems no reason to prefer citation data over cocitation data. In our opinion, more research is needed on whether it can be advantageous to use citation data rather than cocitation data. In addition to the Pearson correlation, other normalizations (e.g., the cosine) also could be taken into account in such research.

\section{References}

Ahlgren, P., Jarneving, B., \& Rousseau, R. (2003). Requirements for a cocitation similarity measure, with special reference to Pearson's correlation coefficient. Journal of the American Society for Information Science and Technology, 54(6), 550-560.

Leydesdorff, L., \& Vaughan, L. (2006). Co-occurrence matrices and their applications in information science: Extending ACA to the Web environment. Journal of the American Society for Information Science and Technology, 57(12), 1616-1628.

McCain, K.W. (1990). Mapping authors in intellectual space: A technical overview. Journal of the American Society for Information Science, 41(6), 433-443.

White, H.D., \& Griffith, B.C. (1981). Author cocitation: A literature measure of intellectual structure. Journal of the American Society for Information Science, 32(3), 163-171. 


\section{Publications in the Report Series Research ${ }^{*}$ in Management}

\section{ERIM Research Program: "Business Processes, Logistics and Information Systems"}

2008

An Evolutionary Framework for Determining Heterogeneous Strategies in Multi-Agent Marketplaces Alexander Babanov, Wolfgang Ketter and Maria Gini ERS-2008-002-LIS

http://hdl.handle.net/1765/10972

Choosing between Auctions and Negotiations in Online B2B Markets for IT Services: The Effect of Prior Relationships and Performance

Uladzimir Radkevitch, Eric van Heck and Otto Koppius

ERS-2008-004-LIS

http://hdl.handle.net/1765/11288

Key Issues in Expansion of End-User Mobile Communication in China

Sunanda Sangwan, Guan Chong and Louis-Francois Pau

ERS-2008-011-LIS

http://hdl.handle.net/1765/11762

Some Comments on the Question Whether Co-Occurrence Data Should Be Normalized

Ludo Waltman and Nees Jan van Eck

ERS-2008-014-LIS

http://hdl.handle.net/1765/11810

Bibliometric Mapping of the Computational Intelligence Field

Nees Jan van Eck and Ludo Waltman

ERS-2008-015-LIS

http://hdl.handle.net/1765/11811

* A complete overview of the ERIM Report Series Research in Management: https://ep.eur.nl/handle/1765/1

ERIM Research Programs:

LIS Business Processes, Logistics and Information Systems

ORG Organizing for Performance

MKT Marketing

F\&A Finance and Accounting

STR Strategy and Entrepreneurship 